\title{
Increasing organismal healthspan by enhancing mitochondrial protein quality control
}

\section{Karin Luce and Heinz D. Osiewacz}

Nat. Cell Biol. 11, 852-858 (2009); published online 21 June 2009; corrected after print 21 December 2011

In the version of this letter initially published online and in print, the order of inserts in Fig. $3 \mathrm{~d}$ had been inverted and the picture in Fig. $4 \mathrm{e}$ was not that of a juvenile hypha from the PaLon_Ox1 strain. The correct order of panels in Fig. 3d and a picture of a juvenile hypha from the PaLon_Ox1 strain corresponding to the experiment in Fig. 4e are provided below. These errors have been corrected in the HTML and PDF versions of the letter. The original conclusions of the paper remain unchanged.

Figure 3
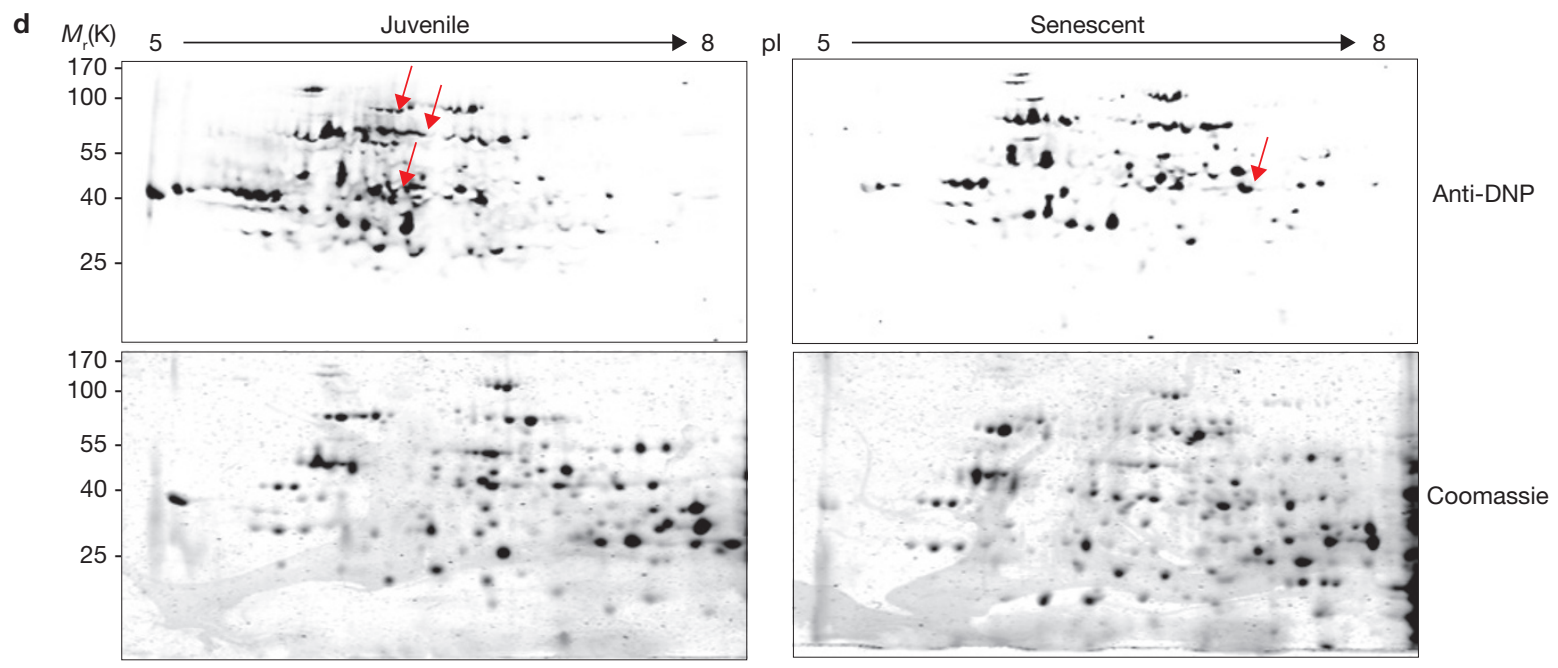

Figure 4

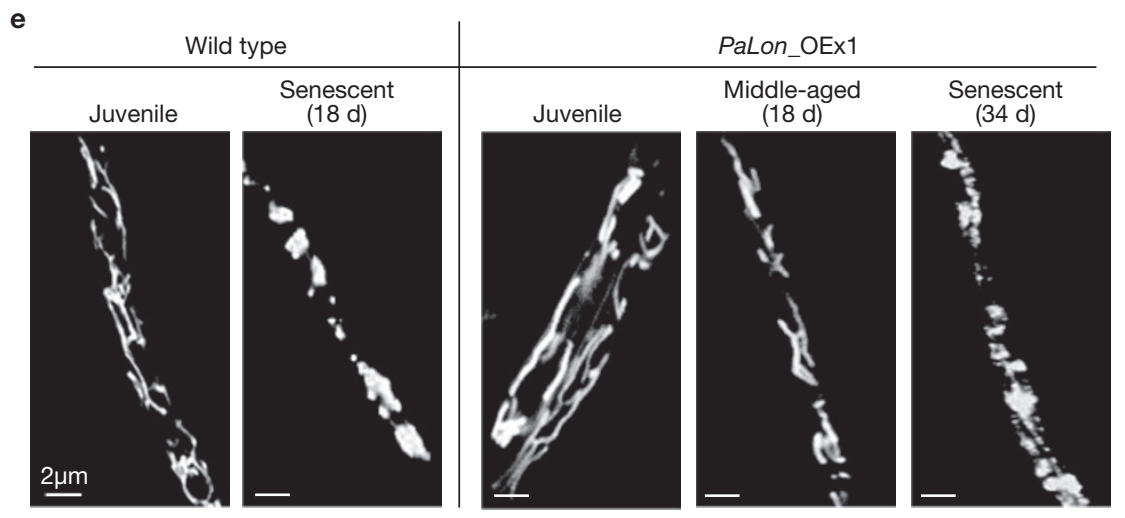

